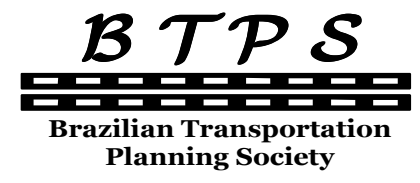

Planning Society

\author{
Journal of Transport Literature \\ Vol. 8, n. 1, pp. 159-177, Jan. 2014 \\ Research Directory
}

JTL|RELIT

www.transport-literature.org

\title{
A alocação de slots e a concorrência no setor de transporte aéreo
}

[Slot allocation and the competition in the Brazilian air transport industry]

\author{
Beatriz Malerba Cravo* \\ Fundação Getulio Vargas, Brasil
}

Submitted 17 Dec 2012; received in revised form 16 Jan 2013; accepted 21 Jan 2013

\begin{abstract}
Resumo
Este trabalho analisa o histórico regulatório do setor de aviação civil e o controle estatal exercido por meio de políticas regulatórias ao longo das décadas. Avalia, no contexto atual, o acesso à infraestrutura necessária para a prestação do serviço de transporte aéreo e suas barreiras à entrada, notadamente as normas para distribuição de slots. São analisadas diferentes possibilidades para a alocação de slots de modo a não limitar a concorrência no setor e garantir o acesso de novos entrantes ao mercado: slot swap, cotas, filas e leilão primário. A alocação de slots no Brasil reflete o passado histórico do setor de aviação civil, sendo que não há uma solução que harmonize com perfeição os interesses das companhias aéreas já consolidadas com a fomentação da concorrência. Este trabalho analisa as diferentes possibilidades, indicando a contribuição de cada uma para um ambiente mais competitivo, bem como seus pontos negativos vis a vis o cenário já consolidado no setor.
\end{abstract}

Palavras-Chave: aviação, transporte, slots, barreiras, concorrência.

\begin{abstract}
This paper analyzes the regulatory history of the airline industry and the state control exercised through regulatory policies over the decades. Evaluation of the current access to the necessary infrastructure for the air transport service and its barriers to entry, notably the rules for allocation of slots. Analysis of different possibilities for the allocation of slots so as not to limit competition in the industry and ensure access for new entrants to the market: slot swap, odds, lines and primary auction. The allocation of slots in Brazil reflects the past history of the airline industry, and there is not a solution that harmonizes perfectly with the interests of airlines companies already consolidated with the fostering of competition. This paper analyzes the different possibilities, indicating the contribution of each to a more competitive environment, as well as its disavantages vis a vis the scenario already consolidated in the industry.
\end{abstract}

Key words: aviation, transportation, slots, barriers, competition.

*Email: bmc@gcba.com.br.

\section{Recommended Citation}

Cravo, B. M. (2014) A alocação de slots e a concorrência no setor de transporte aéreo. Journal of Transport Literature, vol. 8, n. 1, pp. 159-177.

JTL/RELIT is a fully electronic, peer-reviewed, open access, international journal focused on emerging transport markets and published by BPTS - Brazilian Transport Planning Society. Website www.transport-literature.org. ISSN 2238-1031.

This paper is downloadable at www.transport-literature.org/open-access. 


\section{Introdução}

O presente trabalho trata do sistema adotado pela Agência Nacional de Aviação Civil (ANAC) para a alocação de slots e suas implicações para a concorrência no setor de aviação civil e transporte aéreo. Verifica-se que o sistema atual dá preferência às companhias aéreas já consolidadas, em razão do histórico regulatório do setor, criando barreiras à entrada de novos competidores e impedindo a concorrência efetiva entre os agentes econômicos. Serão analisadas diferentes possibilidades para a alocação de slots: slot swap, cotas, filas e leilão primário, a fim de verificar a contribuição de cada uma delas à fomentação da concorrência, bem como seus pontos negativos, em razão do sistema já consolidado no Brasil.

O objetivo aqui desenvolvido é o de apontar os prejuízos à concorrência causados pelo sistema atualmente em vigor, principalmente em razão do histórico regulatório do setor, já que, por muito tempo, a intervenção estatal impedia a competição entre as companhias que nele atuavam. Ademais, serão discutidas novas alternativas, a fim de incentivar a adoção de medidas que possibilitem a efetiva concorrência entre as companhias aéreas, aumentando também com isso o bem estar do consumidor.

Historicamente, o setor de aviação civil foi marcado por períodos de intenso controle estatal. Por meio de políticas regulatórias, o Estado intervinha diretamente na prestação deste serviço, estabelecendo políticas tarifárias e fixando o número de competidores a atuar nos determinados mercados, definidos pelas rotas alocadas às companhias aéreas. Com o início da política de "Flexibilização", as empresas passaram a atuar com mais liberdade, inclusive de preços, fomentando a competição, barateando o serviço e modificando toda a estrutura do setor.

Porém, o aumento da demanda do transporte aéreo não foi acompanhado na mesma proporção pela infraestrutura correspondente, exigida ao atendimento das necessidades das companhias aéreas, bem como de seus passageiros. Afinal, apesar de o número de companhias aéreas e de passageiros ter aumentado, os aeroportos continuaram praticamente os mesmos. Isto se verifica pela frequente superlotação em alguns aeroportos, como Congonhas, em São Paulo, noticiada pela mídia. $\mathrm{O}$ que se verifica atualmente é que o acesso limitado à infraestrutura 
aeroportuária representa uma das principais barreiras ao desenvolvimento do setor, bem como à entrada de novas empresas no mercado.

Nos aeroportos de grande movimentação, os chamados aeroportos "coordenados" (Resolução ANAC n. 2 de 2006) ${ }^{1}$, o espaço físico e o tempo para operação são extremamente limitados. Atualmente, o único aeroporto coordenado existente é o aeroporto de Congonhas, em São Paulo, sendo que existem alguns aeroportos com restrições em horários de pico, entre eles o Aeroporto de Guarulhos. A solução encontrada pelo regulador, a Agência Nacional de Aviação Civil (ANAC), para tentar organizar a oferta de serviço, incompatível com a infraestrutura existente, foi a disponibilização de slots (faixa de tempo relacionada a um determinado espaço disponibilizado à companhia aérea para pouso e decolagem).

A alocação de slots é considerada hoje a maneira mais eficiente de organizar o acesso dos diversos competidores à infraestrutura necessária. Ocorre que esta forma de alocação, ainda que busque igualar as oportunidades dos agentes econômicos atuantes neste mercado, também acaba por impedir o desenvolvimento de um mercado competitivo, podendo até mesmo favorecer a formação de um poder de monopólio. Isto porque a alocação dos slots às companhias aéreas já consolidadas pode impedir que outras empresas ingressem naquele mercado, ou então que outros concorrentes participem das rotas mais rentáveis, contribuindo para a manutenção do poder econômico destas companhias aéreas e diminuindo o bem-estar do consumidor.

O presente artigo objetiva apresentar brevemente o histórico regulatório do setor de aviação civil até a adoção pela ANAC do sistema de alocação de horários de voos no Brasil (Resolução ANAC n. 2 de 2006), destacando os possíveis efeitos anticompetitivos que as medidas adotadas pelo órgão regulador podem causar. Analisa o acesso à infraestrutura necessária para a prestação do serviço de transporte aéreo e suas barreiras à entrada, especificamente as normas para distribuição de slots. Ademais, busca avaliar diferentes possibilidades de alocação dos slots: slot swap, cotas, filas e leilão primário, indicando seus

1 Art. $2^{\circ}$ Para os fins deste Regulamento, considera-se: (...) II - aeroporto coordenado: é aquele onde a expansão de capacidade, a curto prazo, é altamente improvável e a demanda por facilidades excede as possibilidades aeroportuárias, causando saturação em determinadas faixas de horário e durante um período de tempo relevante, implicando em que as tentativas de resolver os problemas por meio de modificações voluntárias de horário normalmente não são bem sucedidas, tendo as empresas que receber a alocação de slots para operar no aeroporto. 
pontos positivos e negativos, a fim de garantir maior competitividade neste setor, cada vez mais importante para o país.

Deste modo, a primeira seção irá tratar dos marcos regulatórios no setor de transporte aéreo, indicando suas principais consequências e contribuições para a competição (ou ausência de) verificada atualmente. A segunda seção fará uma análise das barreiras à entrada no mercado de transporte aéreo, notadamente a escassa infraestrutura aeroportuária. A terceira seção analisa a competitividade no setor e o papel da ANAC como órgão regulador. Ainda, demonstra como a alocação de slots pode conferir poder econômicos aos agentes do mercado. Por fim, a quarta seção avalia as diferentes possibilidades de alocação dos slots: slot swap, cotas, filas e leilão primário, indicando suas vantagens e desvantagens. Conclui-se que, apesar de não haver uma solução ideal, que harmonize os interesses de companhias consolidadas e novas entrantes, resta evidente a necessidade de adoção de um sistema de alocação de slots mais igualitário.

\section{Marcos regulatórios no setor de transporte aéreo}

Do final dos anos 1960 e início da década de 1970 até os dias atuais, o setor de transporte aéreo passou por diversos momentos regulatórios, que podem ser divididos em seis principais estágios: (i) Regulação com política industrial (1973-1986); (ii) Regulação com política de estabilização ativa (1986-1992); (iii) Liberalização com política de estabilização inativa (1992-1997); (iv) Liberalização com restrição de política de estabilização (1998-2001); (v) Quase-desregulamentação (2001-2002); e (vi) Re-regulação (a partir de 2003). Pode-se destacar como marcos regulatórios significativos a adoção de mecanismos de desenvolvimento regional no início dos anos 1970 e a política de "Flexibilização", introduzida no início da década de 1990 (Oliveira, 2005).

O primeiro período, da regulação com política industrial, foi um dos mais representativos da era regulatória do setor. Isto porque as autoridades tinham por objetivo implementar instrumentos de regulação juntamente com mecanismos desenvolvimentistas. Neste período, foi estabelecido o SITAR (Sistema Integrado de Transporte Aéreo Regional), que delimitou uma estrutura para o transporte aéreo consubstanciada em quatro companhias nacionais e cinco companhias regionais. 
Marcado pela forte intervenção estatal, as variáveis preço e frequência de voo eram fixadas pelas autoridades regulatórias. O país foi dividido em cinco áreas, as quais seriam exploradas sob regime de monopólio, sendo que cada uma delas foi atribuída a uma das cinco companhias regionais. Não era permitida a entrada de novas companhias no mercado. As companhias nacionais não podiam competir com as regionais, devendo atuar somente em ligações "tronco" (regime de competição controlada). Cabia às quatro companhias nacionais toda a operação do sistema.

O segundo período foi caracterizado pelo desgaste das políticas industriais e pela forte intervenção nas políticas de reajustes tarifários. Os preços foram fixados artificialmente muito abaixo dos preços reais, causando grandes prejuízos às companhias aéreas (contestados judicialmente) (Oliveira, 2005).

O terceiro estágio marcou o início da política de Flexibilização, por meio de um conjunto de portarias expedidas pelo extinto Departamento de Aviação Civil (DAC). Neste período, foi realizada a Primeira Rodada de Liberalização, a partir da qual foram abolidos os monopólios regionais, que já vinham apresentando distorções em razão da crescente competição entre eles. Com o fim do regime de competição controlada, passou-se então a estimular a entrada de novas operadoras no mercado. Algumas exceções continuaram sob o monopólio das companhias regionais. Eram as chamadas "Linhas Aéreas Especiais", formadas por pares de aeroportos que ligavam as cidades de São Paulo, Rio de Janeiro, Belo Horizonte e Brasília.

No quarto período ocorreu a Segunda Rodada de Liberalização, caracterizada por estimular o primeiro grande surto de competitividade desde o início da desregulamentação. Também foi determinado o fim da exclusividade das regionais em operarem as "Linhas Aéreas Especiais". Ocorre que o período também foi marcado pela forte instabilidade da taxa de câmbio e pela desvalorização do Real frente ao Dólar. Isto gerou um aumento dos preços e resultou na volta do controle de preços.

No quinto período, a partir de 2001, a maioria dos mecanismos de regulação foi removida e foi colocada em prática uma total liberalização dos preços. Ocorreu a Terceira Rodada de Liberalização e houve a flexibilização dos processos de entrada de novas empresas e pedidos de novas linhas aéreas, frequências de voos e aviões. 
Por fim, o sexto período, iniciado em 2003, voltou a implementar alguns mecanismos de interferência econômica no mercado. Foram editadas novas portarias ${ }^{2}$ e o DAC passou a exercer uma função moderadora, a fim de adequar a oferta de transporte aéreo à evolução da demanda. Neste período, os pedidos de importação de novas aeronaves, novas linhas e até mesmo a entrada de novas companhias aéreas, voltaram a exigir estudos prévios de viabilidade econômica. Foi um período bastante semelhante ao período regulatório típico, porém, sem a re-regulação tarifária. Ou seja, não havia interferência nos preços praticados pelas companhias aéreas. O objetivo aqui é controlar o excesso de capacidade das companhias aéreas e a chamada "competição ruinosa", que poderiam resultar na baixa qualidade dos serviços prestados aos passageiros e na autoflagelação das próprias companhias. Isto porque, na tentativa de oferecer preços cada vez mais baixos, as companhias poderiam operar abaixo do seu preço custo, o que poderia resultar em sua falência. (Oliveira, 2005).

\section{Infraestrutura aeroportuária e barreiras à entrada}

A atividade de transporte aéreo no Brasil apresenta diversos obstáculos para aqueles que desejam ingressar neste mercado. A começar pela própria concessão do serviço público e todas as exigências burocráticas a ela relacionadas. Os requisitos para a concessão do serviço de transporte aéreo são estabelecidos pelo Código Brasileiro de Aeronáutica (CBA) ${ }^{3}$, regulamentados pela Portaria n. 536/GC5/1999.

Observa-se ainda que a referida Portaria exige, para que seja concedida a autorização para funcionamento jurídico da companhia aérea, que seja realizado um estudo de viabilidade

\footnotetext{
${ }^{2}$ Destacam-se as portarias 243/CG5, de 13 de março de 2003 e a 731/CG5, de 11 de agosto de 2003.

${ }^{3}$ Art. 181. A concessão somente será dada à pessoa jurídica brasileira que tiver:

I - sede no Brasil; II - pelo menos 4/5 (quatro quintos) do capital com direito a voto, pertencente a brasileiros, prevalecendo essa limitação nos eventuais aumentos do capital social; III - direção confiada exclusivamente a brasileiros. $\S 1^{\circ}$ As ações com direito a voto deverão ser nominativas se se tratar de empresa constituída sob a forma de sociedade anônima, cujos estatutos deverão conter expressa proibição de conversão das ações preferenciais sem direito a voto em ações com direito a voto. $\S 2^{\circ}$ Pode ser admitida a emissão de ações preferenciais até o limite de $2 / 3$ (dois terços) do total das ações emitidas, não prevalecendo as restrições não previstas neste Código. $\S 3^{\circ} \mathrm{A}$ transferência a estrangeiro das ações com direito a voto, que estejam incluídas na margem de 1/5 (um quinto) do capital a que se refere o item II deste artigo, depende de aprovação da autoridade aeronáutica. $\S 4^{\circ}$ Desde que a soma final de ações em poder de estrangeiros não ultrapasse o limite de $1 / 5$ (um quinto) do capital, poderão as pessoas estrangeiras, naturais ou jurídicas, adquirir ações do aumento de capital.
} 
econômica para a implantação de todos os elementos do empreendimento pretendido ${ }^{4}$. No entanto, os parâmetros e critérios estabelecidos para a avaliação econômico-financeira da empresa não são suficientemente claros e objetivos, o que gera dúvidas quanto aos requisitos a serem atendidos pelas empresas e eleva o nível de discricionariedade da autoridade de aviação civil, ocasionando demora desnecessária no processo de concessão (Reis, 2009).

Devem também ser consideradas as limitações financeiras, já que os investimentos estrangeiros são limitados a $20 \%$ (vinte por cento) do capital social da empresa, de acordo com o art. 181 do $\mathrm{CBA}^{5}$; e as restrições regulatórias, que, junto com a escassez de infraestrutura, são consideradas as principais barreiras à entrada. A aviação comercial internacional é objeto de forte regulação estabelecida em acordos bilaterais. Estes acordos definem a quantidade e tipos de voos que poderão ser realizados entre dois países e possuem como referência o rol das chamadas "liberdades do ar", que constituem diferentes tipos de direitos de entrada, pouso e operação de aeronaves em territórios de outros Estados ${ }^{6}$.

Ademais, existem outros fatores menos relevantes, mas que também podem constituir dificuldades para novos entrantes neste mercado. São eles: programas de fidelidade, na medida em que tendem a beneficiar as companhias já instaladas e que possuem mais opções de destino dentro de sua malha aeroviária; alianças globais, tais como Star Alliance, SkyTeam e Oneworld, que podem não aceitar a companhia entrante como sua signatária, o que a coloca em condição de desigualdade junto a seus concorrentes (CADE, 2011).

Atualmente, a principal dificuldade a ser enfrentada por um novo entrante no mercado de transporte aéreo é a alocação de infraestrutura aeroportuária. Isto porque os principais

\footnotetext{
${ }^{4}$ Art $2^{\circ}$ - O pedido de autorização para funcionamento jurídico será dirigido ao Diretor-Geral do Departamento deAviação Civil, instruído com os seguintes documentos: (...) V - projeto de constituição da empresa demonstrando o planejamento estratégico do empresário para o empreendimento proposto, contemplando claramente as diversas fases do projeto (implantação, consolidação e expansão) com a descrição, em cada uma delas, da frota e dos mercados a serem servidos e contendo um estudo de viabilidade econômica para a fase de implantação, com todos os elementos que fundamentem a adequabilidade do capital social inicial proposto ao empreendimento pretendido.

${ }^{5}$ O PL 6716/2009, em trâmite na Câmara, propõe o aumento do teto para 49\%. O texto foi aprovado em 23 de junho de 2010 pela Comissão Especial formada para o projeto e desde então aguarda votação pelo Plenário. Disponível em < http://www.camara.gov.br/proposicoesWeb/fichadetramitacao?idProposicao=465324 > Acesso em 25 de junho de 2012.

${ }^{6}$ Brasil. Conselho Administrativo de Defesa Econômica (CADE). Ato de Concentração n. 08012.009497/201084. Relator: Conselheiro Olavo Chinaglia. Brasília. J. em: 14/12/2011. Disponível em < http://www.cade.gov.br/temp/D_D000000642521522.pdf > Acesso em 24 de junho de 2012.
} 
aeroportos brasileiros (de maior circulação) não possuem mais espaço para novas empresas, já que sua estrutura foi distribuída entre as únicas companhias atuantes à época da divisão. Verifica-se a existência de grande demanda reprimida, já que nesses aeroportos existem poucos e concentrados concorrentes. Trata-se de reflexo do histórico da aviação doméstica brasileira, que, como mencionado acima, consistia de um mercado oligopolizado, em que nunca havia mais do que três ou quatro concorrentes.

Com a política de "Flexibilização" e o aumento da competitividade no setor, houve um crescimento acelerado do mercado aéreo no país. Verificou-se o surgimento da política de baixo custo, o que aumentou ainda mais a competitividade entre as companhias e estimulou a busca pelo menor preço. Como consequência, cresceu também o índice de pedidos de concessão para novas empresas, bem como pedidos de ampliação da malha aérea por aquelas empresas que já atuavam no mercado (Braga, 2009).

Ocorre que este aumento da demanda não foi acompanhado de políticas públicas para o setor, sendo que as estruturas ficaram congestionadas de tal forma que passaram a comprometer a qualidade dos serviços prestados e a segurança dos passageiros. Foi preciso então encontrar um meio de distribuir o pouco espaço disponível entre as companhias existentes, a fim de otimizar a utilização daquela infraestrutura essencial (Braga, 2009).

\section{A ANAC e a competitividade no setor de transporte aéreo}

A Agência Nacional de Aviação Civil (ANAC) foi instituída pela Lei 11.182, de 27 de setembro de 2005. Trata-se de uma autarquia especial, vinculada ao Ministério da Defesa, e é a autoridade aeronáutica do país. Ela possui a competência de regular e fiscalizar as atividades da aviação civil, da infraestrutura aeroportuária, além de ter a obrigação de observar e implementar estratégias, políticas e diretrizes estabelecidas pelo Conselho de Aviação Civil (CONAC) (Abreu, 2008).

Um dos grandes desafios a serem enfrentados pela ANAC, como autoridade reguladora, é a questão da limitação do acesso à infraestrutura por meio da alocação de slots. Isto porque pode-se afirmar que a concessão do slot é uma maneira de conferir poder de mercado a uma companhia aérea, já que é a única forma de ela agir no mercado em que atua. 
Por esta razão, é preciso que se alcance uma solução equilibrada, em que as companhias já estabelecidas não percam os investimentos realizados e, ao mesmo tempo, sejam conferidas às novas entrantes as mesmas oportunidades e condições das primeiras.

Diante desse cenário, a ANAC vem estudando uma nova maneira de garantir o acesso à infraestrutura por todos os agentes do mercado, inclusive os novos entrantes ${ }^{7}$. Observa-se que o fomento à competitividade não depende somente da alocação de slots, sendo que a ANAC deve empenhar esforços também em aspectos que podem contribuir para a desconcentração da demanda aeroportuária dos grandes centros urbanos, diminuindo o fluxo de passageiros dos chamados aeroportos coordenados.

Entre esses aspectos estão a privatização dos aeroportos, a regulação de atrasos e cancelamentos de voos, a prática do overbooking e a melhoria da infraestrutura aeroportuária, inclusive dos aeroportos localizados fora do eixo de maior concentração econômica (Braga, 2009). Ainda assim, é essencial que se encontre uma maneira equitativa de alocar a escassa infraestrutura encontrada em alguns aeroportos.

\subsection{Alocação de slots}

No setor de transporte aéreo, o termo slot refere-se a uma faixa de tempo e relaciona-se a um determinado espaço que uma companhia aérea utiliza para que sua aeronave, em determinada rota, possa realizar os procedimentos de aterrissagem e decolagem em um aeroporto. Assim, faz parte do slot o intervalo de tempo do procedimento que está associado às instalações: pista, estacionamento, portão de embarque e desembarque de passageiros, ou seja, toda e qualquer infraestrutura referente à aterrissagem e decolagem (Ministério da Fazenda, SEAE, 2006).

De maneira geral, a alocação dos slots é feita por meio de conferências realizadas pela Iternational Air Transportation Association (IATA). Estas conferências ocorrem duas vezes ao ano, quando se reúnem representantes de aproximadamente 213 aeroportos do mundo e representantes de todas as companhias aéreas internacionais, com o objetivo de definir a

\footnotetext{
7 Em 2008, a ANAC lançou consulta pública para uma nova resolução sobre o tema. Disponível em < http://www2.anac.gov.br/transparencia/consultasPublicasEncerradas2008.asp > Acesso em 25 de junho de 2006.
} 
alocação de slots nos aeroportos coordenados. Cada aeroporto possui um coordenador de slot e a alocação é feita da seguinte forma (Fiuza e Pioner, 2009):

1) Cada linha aérea submete uma proposta de horários de pouso e decolagem para cada coordenador de slot de aeroporto 6 meses antes da temporada;

2) Os coordenadores alocam os slots de acordo com a regulação vigente: grandfather rules e use-it-or-lose-it rules para os slots que já estavam disponíveis e uma regra de 50\% para entrantes para o pool que reúne os slots devolvidos e os novos slots resultantes, ou de aumento de capacidade, ou de otimização dos procedimentos de pouso e decolagem;

3) A alocação inicial é apresentada no início da conferência para as linhas aéreas;

4) As linhas aéreas então passam a trocar slots entre si, de acordo com a conveniência;

5) As linhas aéreas então podem submeter outras propostas de voos, usando diferentes tipos de aeronaves, para os coordenadores de slots, de modo a otimizar a operação dos slots remanescentes;

6) Os coordenadores de slots avaliam, então, se a capacidade das demais instalações do aeroporto comporta os diferentes tipos de aeronaves propostos.

No Brasil, a alocação de slots às companhias aéreas, regulamentada pela Resolução n. 002/2006 da Agência Nacional de Aviação Civil (ANAC), foi a forma encontrada pela autoridade reguladora para distribuir equitativamente os escassos recursos de infraestrutura existentes nos aeroportos de grande circulação, os chamados aeroportos coordenados. Tal mecanismo recebe disciplina regulatória e deve ser exercida pelo poder concedente do serviço público, no caso, a $\mathrm{ANAC}^{8}$. Isto significa que devem ser observados os princípios da universalidade, regularidade, continuidade, eficiência e segurança (Braga, 2009).

A Resolução n. 002/2006 da ANAC estabelece alguns critérios que devem ser observados para a alocação de slots. São eles (Braga, 2009):

1) Organização de duas grades de rodízio em cada aeroporto coordenado (aeroportos com limitações estruturais, que precisam do sistema de slots), sendo uma destinada às companhias que já atuam no aeroporto, na proporção de $4 / 5$ de pares de slots $^{9}$ e outra destinadas às entrantes, na proporção de $1 / 5$ de pares de slots.

2) Possibilidade de realocação dos slots quando a empresa concessionária (i) não tiver implantado o serviço no prazo de 30 dias a contar da alocação; (ii) não atingir índice de regularidade mensal igual ou superior a $80 \%$ da operação prevista durante o período de 90 dias consecutivos (ou seja, se

\footnotetext{
${ }^{8}$ Lei 11.182 , de 27 de setembro de 2005.

${ }^{9} \mathrm{O}$ par de slots é o horário de chegada e o horário de partida da aeronave no aeroporto coordenado.
} 
houver mais de $20 \%$ de cancelamentos no período); (iii) deixar de utilizar o par de slots por período superior a 30 dias consecutivos; (iv) manifestar desinteresse na exploração do slot.

3) Possibilidade da implantação de sistema de rodízios, condicionada à demonstração da capacidade técnica da concessionária.

Ocorre que, ainda que a ANAC tenha objetivado distribuir os recursos de maneira justa e equitativa, na prática, o que se verifica é que, com a superlotação dos aeroportos, as novas entrantes não conseguem slots nos aeroportos coordenados. Ou seja, a despeito de todo o investimento que uma nova companhia deve realizar, conforme mencionado acima, ela não consegue atuar nos mercados (rotas) mais lucrativos. Pelo menos não em condições de igualdade com as companhias já estabelecidas.

Ora, uma companhia que acaba de ingressar no mercado não conseguirá espaço, por exemplo, no Aeroporto de Congonhas, em São Paulo, um dos aeroportos de maior circulação do país, em razão de todos os slots já estarem alocados a outras companhias. Então, sua única opção acaba sendo utilizar outros aeroportos, mais afastados da cidade, que podem não ser tão atraentes aos olhos dos passageiros, em razão da praticidade e facilidade de acesso.

Isto significa que ela deverá investir mais em outros fatores, como qualidade do serviço, conforto das aeronaves, pontualidade, frequência de voos, etc. para conseguir atrair a confiança de seu cliente e assim conseguir uma parcela daquele mercado. Enquanto as outras companhias, além de já estarem estabelecidas naquele mercado, não precisarão de tantos esforços para manter a sua clientela, pela simples razão de contarem com uma melhor localização, o que pode resultar na diminuição do bem-estar do consumidor.

Afinal, se a rivalidade é insuficiente para desafiar as empresas que já possuem atuação dominante em determinado aeroporto, a qualidade dos serviços prestados aos passageiros pode cair sem que a empresa diminua a sua lucratividade. Na prática, o que se verifica é que os passageiros estão cada vez mais insatisfeitos com os serviços prestados pelas companhias aéreas. Os problemas enfrentados são diversos: atrasos e cancelamentos de voos, deficiência nas informações prestadas aos passageiros, comprometimento da segurança, entre outros. Porém, ao passageiro não resta alternativa, já que ele precisa daquele serviço e não há outra prestadora a quem recorrer.

Assim, é possível concluir que a limitação da infraestrutura aeroportuária consiste em significativa barreira à entrada no mercado de transporte aéreo, representando um 
desincentivo de investimento aos novos entrantes, que poderão desistir de concorrer naquele mercado, por todas as razões demonstradas acima. Isto prejudica a competitividade no setor, contribuindo de certa forma para a concentração do mercado em apenas alguns poucos competidores.

\title{
3.1.1 Alocação de slots como forma de manutenção do poder econômico
}

Diante da escassez de infraestrutura que se verifica em alguns aeroportos, (aqueles que, em regra, fazem parte das rotas mais lucrativas), pode-se dizer que o slot é um meio de sustentação do poder econômico da empresa. Ainda, considerando que se trata de infraestrutura da qual o Poder Público não dispõe para oferecer a novos entrantes, as empresas já consolidadas operam com a "tranquilidade" de que não há espaço para novos concorrentes (Braga, 2009).

O próprio Conselho Administrativo de Defesa Econômica (CADE), na análise da operação de fusão das empresas TAM e LAN, reconheceu que a insuficiência de infraestrutura em determinados aeroportos é uma preocupação concorrencial não somente no Brasil, mas também em outras partes do mundo, como Europa e Estados Unidos.

\begin{abstract}
Há um consenso nas análises da indústria de aviação de que a principal barreira à entrada de novos agentes no setor refere-se à insuficiência de infraestrutura em determinados aeroportos. Conforme observou Borenstein, grande parte das análises sobre o setor de transporte aéreo aponta escassez de capacidade aeroportuária como o fator concorrencial crítico.
\end{abstract}

Tal fenômeno também é reconhecido por diferentes autoridades de defesa da concorrência (CADE, 2011).

Em seu voto, o Conselheiro-Relator Olavo Chinaglia mencionou um caso recente julgado pela Comissão Europeia ${ }^{10}$, que reconhece a indisponibilidade de slots como uma dificuldade aos novos entrantes:

Indisponibilidade de slots é reconhecida por constituir a principal barreira a entrada ou expansão em casos de aviação e a liberação de slots tem sido o principal remédio endereçado a preocupações concorrenciais em casos antitruste (CADE, 2011).

Como ressalta Oliveira (2009), ainda que a normatização da alocação de slots tenha organizado a prestação do serviço de transporte aéreo pelas companhias aéreas regulares, a

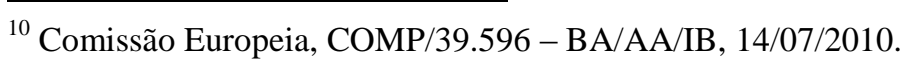


implementação da regra acabou por preservar as participações de mercado das companhias dominantes. De acordo com o autor, serviu como a consolidação do sistema de grandfather rights:

Os chamados grandfather rights retratam uma situação típica do transporte aéreo mundial, na qual a dominância histórica das companhias aéreas em um dado aeroporto se torna institucionalizada pelas próprias regras que governam aquele aeroporto, isto é, todo o arcabouço normatizador da rotina aeroportuária acaba sempre por consolidar a dominância dos agentes de operação aérea.

Assim, reforça-se a importância de as autoridades reguladora e de defesa da concorrência buscarem o equilíbrio entre as companhias aéreas já consolidadas e aquelas que pretendem ingressar no mercado de transporte aéreo. Enquanto as primeiras não devem ser prejudicadas, já que realizaram investimentos para alcançarem a posição que ocupam e a infraestrutura de que dispõem, às demais também deve ser dada a mesma oportunidade, para que haja a manutenção de um ambiente concorrencial saudável.

\section{Transferência e redistribuição de slots}

Considerando a escassez de infraestrutura em alguns aeroportos e a grande disputa entre as companhias aéreas, verifica-se no Brasil e também em outros países, como Estados Unidos, que os slots passaram a ser considerados como se fossem ativos das companhias aéreas, agregando a elas considerável valor econômico. A aquisição de slots foi, inclusive, a razão pela qual as companhias atualmente dominantes no Brasil, como TAM e Gol, conquistaram suas posições no mercado e, principalmente, nos aeroportos de grande circulação.

No entanto, é preciso observar que, tecnicamente, os slots não são propriedade das companhias aéreas. Nos Estados Unidos, o slot é definido como "a reserva de um horário para o pouso ou decolagem de uma aeronave de uma determinada linha aérea". Na Europa, o slot é definido como "a permissão de uma linha aérea para usar toda a infraestrutura aeroportuária necessária para operar uma rota aérea em um aeroporto coordenado numa data e horário específico com o propósito de pouso ou decolagem". Nenhum deles faz referência a qualquer direito de propriedade sobre o slot por parte da companhia aérea, sendo que cabe aos aeroportos ou autoridades regulatórias a alocação dos slots conforme entenderem conveniente (Fiuza e Pioner, 2009). 
No Brasil, o termo slot se refere a "uma faixa de tempo e relaciona-se a um determinado espaço, que uma companhia aérea utiliza para que sua aeronave, em determinada rota, possa realizar os procedimentos de aterrissagem e decolagem em um aeroporto". Seu uso pelas companhias aéreas não decorre de propriedade, mas sim de decisão da autoridade competente (ANAC). Assim, não é possível falar em alienação, transferência ou doação de slots. Porém, é possível que as empresas permutem slots entre si, na base de um para um, estratégia que será melhor analisada a seguir (Fiuza e Pioner, 2009).

Como demonstrado acima, o contexto histórico e regulatório do setor de transporte aéreo favoreceu algumas empresas. No período da regulação com política industrial, quando havia o SITAR, foram favorecidas principalmente as companhias nacionais, a quem competia a organização de todo o sistema.

Mesmo após o período da re-regulação, o mercado disponível aos novos competidores sempre foi muito restrito, sendo que as empresas tradicionais estavam muito a frente daqueles que desejavam ingressar no mercado. Assim, foram realizadas muitas aquisições sem que fossem devidamente consideradas as suas implicações para o cenário competitivo. Como destacado por Braga (2009, p. 152), estas aquisições foram construindo a estrutura de mercado que hoje se verifica:

\begin{abstract}
A Varig tornou-se a maior potência dentre as nacionais, exatamente porque era detentora da Cruzeiro até o ano de 1992 e antes disso já possuía parte da Real e da Panair. Mais tarde incorporaram à Varig, a Rio-Sul e Nordeste. Enquanto reinava soberana a Varig, outra companhia seguia seus exemplos. A TAM obtinha o controle da Brasil-Central, Helisul e Itapemirim-Regional. Não houve concorrência imposta pela Transbrasil, porquanto esta possuía apenas uma regional e a Vasp não realizou qualquer operação de fusão ou incorporação com outras companhias menores. Assim, pode-se afirmar que TAM e Varig já vivenciaram um oligopólio no passado, tal como a primeira, hoje, mantém a Gol.
\end{abstract}

Hoje o que se verifica é praticamente um duopólio nos principais aeroportos do país entre TAM e Gol, sendo que a própria Gol se beneficiou da aquisição dos slots pertencentes à Varig. Como demonstrado, a aquisição de companhias aéreas com o objetivo de "herdar" seus slots é um mecanismo comum no Brasil, já que o slot acaba sendo transferido para a empresa adquirente na condição de um ativo (bastante valioso, cumpre destacar) da empresa adquirida. Aliás, vale destacar que a operação de aquisição da Varig pela Gol teria um valor muito menor se não fosse pela transferência dos slots. 
No entanto, a venda de uma companhia aérea ou o encerramento de suas atividades pode ser o grande momento de redistribuição de seus slots a outros interessados, principalmente os novos entrantes, que possuam pequena ou nenhuma atuação nos aeroportos coordenados. A seguir, serão apresentadas e analisadas algumas possibilidades para a alocação de slots,

\section{1 “Slot Swap” e sua aplicação no Brasil}

Nos Estados Unidos, vem sendo aceita pelas autoridades regulatórias a prática de "slot swap". Por meio desta prática, as companhias podem transacionar entre si os slots que possuem.

Este foi o caso da Delta e da US Airways. As duas companhias fizeram um acordo por meio do qual a Delta receberia da US Airways 132 pares de slots no aeroporto LaGuardia, em Nova Iorque, enquanto a US Airways receberia da Delta 42 pares de slots no aeroporto Reagan National, em Washington, e o direito de operar um serviço diário adicional para São Paulo, em 2015. Ainda, a Delta pagaria à US Airways o valor de US\$ 66,5 milhões ${ }^{11}$.

No Brasil, esta prática também é adotada pelas companhias aéreas. Esta foi, inclusive, a solução adotada pelo CADE no julgamento da fusão entre as empresas LAN e TAM. O CADE aprovou a operação com a condição de que fosse realizada pelas empresas a permuta de slots e infraestrutura aeroportuária conexa no Aeroporto de Guarulhos, de modo a permitir que outras companhias pudessem operar duas frequências diárias na rota São Paulo - Santiago - São Paulo por meio de voos diretos (CADE, 2011).

Durante a análise desta operação, o Superintendente de Regulação Econômica e Acompanhamento de Mercado da ANAC explicou ao CADE que “(...) a permuta de horários (slots) entre as empresas aéreas - swap, visando à otimização da malha aérea de cada uma é permitida, sendo necessário que ambas as empresas encaminhem ao Comitê mensagem SMA (Schedule Movement Advice Message)" (CADE, 2011).

\subsection{Cotas}

Este mecanismo é utilizado principalmente na Europa. Cada aeroporto ou autoridade competente define o número máximo de operações de pouso e decolagem que o aeroporto

\footnotetext{
${ }^{11}$ [s. n.] Disponível em < http://nectar-ita.blogspot.com.br/2011/07/delta-us-airways-slot-swap-finally-gets.html $>$ Acesso em 07 de junho de 2012.
} 
comporta nos horários determinados. Os slots são então alocados entre as companhias aéreas de acordo com as conferências da IATA, sendo que é possível a transferência ou venda entre as companhias, desde que com a anuência do aeroporto (Fiuza e Pioner, 2009).

A crítica que se faz a este sistema é em razão da distribuição de slots ser efetuada com base em critérios de antiguidade (grandfather rule), que não necessariamente prioriza a empresa mais eficiente. A vantagem está na previsibilidade das frequências ao longo do ano. Isto porque há pouca variação na alocação do slot, de modo que as companhias podem planejar a venda de bilhetes a longo prazo com baixo risco de serem impedidas de operar naquele horário (Fiuza e Pioner, 2009).

\subsection{Filas}

Este mecanismo é utilizado principalmente nos Estados Unidos. Por este sistema, as companhias aéreas podem alocar quantos voos quiserem (até um limite), sendo que a permissão para pouso e decolagem será feita com base nos seguintes critérios, estabelecidos pelo Anexo 9 da Convenção de Chicago: 1) voo regular; 2) voo internacional; 3) maior número de passageiros; 4) maior porte da aeronave; 5) voo em trânsito (Fiuza e Pioner, 2009).

Este mecanismo diminui bastante as barreiras aos novos entrantes. Porém, o problema é que ele contribui para o aumento do congestionamento, pois o atraso causado por uma companhia (seja por incluir um novo voo, seja por algum problema) afeta todas as demais (Fiuza e Pioner, 2009).

\subsection{Leilão primário}

Os valores mobiliários são negociados no mercado financeiro por meio de leilões. Eles são inicialmente oferecidos em leilões primários, dos quais participam o Banco Central e as instituições financeiras. Estes leilões obedecem a uma programação previamente estabelecida e são divulgados por meio de comunicados às instituições financeiras através de um sistema do Banco Central, o Sisbacen, e publicados no Diário Oficial da União. São divulgadas informações sobre as condições específicas da oferta, tais como os títulos a serem ofertados, as quantidades, a data de liquidação financeira, o horário para recebimento das ofertas e outras informações importantes. 
Então, uma vez que os títulos são emitidos e colocados em circulação, eles passam a ser negociados no mercado secundário. As instituições financeiras, negociando tanto para sua conta própria como para seus clientes, fornecem cotações de compra e venda nos mais variados papéis $^{12}$.

No caso de alocação de slots de companhias aéreas que estejam sendo adquiridas ou que estejam encerrando suas atividades, este é um sistema que pode ser adotado para a redistribuição dos slots entre os eventuais interessados. Em lugar de simplesmente transferir uma infraestrutura tão essencial e disputada para uma companhia que pode já ser detentora de alto poder econômico, os slots seriam leiloados, permitindo a novos entrantes a oportunidade de atuar nos aeroportos de maior circulação.

Obviamente, a aquisição dos slots em leilão deve observar certos critérios, de modo a dar prioridade àquelas companhias que ainda não estejam consolidadas e que possam oferecer concorrência às companhias tradicionais. Por exemplo, no caso da aquisição da Pantanal pela TAM, os slots alocados à Pantanal não seriam automaticamente transferidos para a TAM, mas sim leiloados, para que outras empresas tivessem a oportunidade de atuar naqueles mercados que estavam sendo deixados pela Pantanal.

Então, após a aquisição primária de slots, por meio de leilão, as companhias poderiam até mesmo comprar e vender entre si os slots adquiridos. Isto sempre com a aprovação do Conselho Administrativo de Defesa Econômica (CADE), para evitar qualquer concentração de poder econômico.

Desta forma, além dos critérios que devem ser obervados na alocação dos slots, tais como regularidade e confiabilidade na prestação do serviço pela companhia, entre outros, o leilão seria uma forma de estabelecer disputa da alocação de slots, o que não ocorre hoje em dia, prevalecendo a melhor proposta, conforme critérios estabelecidos pela própria ANAC.

Esta parece ser a solução mais adequada, pois considera os interesses de todas as partes envolvidas: (i) das companhias já estabelecidas, que serão informadas com antecedência sobre os novos critérios e poderão adequar seus investimentos; (ii) dos novos entrantes, que terão as mesmas oportunidades que seus concorrentes já estabelecidos de disputar espaço nos

\footnotetext{
${ }^{12}$ [s.n.] Disponível em < http://www.portalbrasil.net/cvm.htm $>$ Acesso em 09 de junho de 2012.
} 
mercados mais lucrativos e concorridos; (iii) dos passageiros, que contarão com maior segurança e melhor qualidade no serviço prestado pelas companhias aéreas; e (iv) do Estado brasileiro, que incentivará a atividade de transporte aéreo, garantindo condições igualitárias a todos os agentes que desejem atuar no setor.

Do contrário, os novos entrantes ficarão expostos a mais riscos, limitados aos aeroportos com menor operação e menos lucrativos, o que poderá representar um desincentivo à competitividade no setor. Além disso, ao terem garantidas as suas participações nos mercados mais competitivos, as companhias já estabelecidas deixam de investir na qualidade de seus serviços, o que compromete não somente o bem estar econômico do consumidor, como também a segurança nacional.

\section{Conclusão}

O presente trabalho buscou analisar o histórico regulatório do setor de transporte aéreo no Brasil, a fim de contextualizar os mecanismos adotados pela ANAC nos dias de hoje e suas consequências para o desenvolvimento e competitividade do setor. Ademais, foram avaliadas diferentes possibilidades para a distribuição dos slots, de forma a não limitar a concorrência no setor.

Sabe-se que a importância do transporte aéreo vem aumentando com o desenvolvimento econômico e tecnológico, sendo que, cada vez mais, a agilidade no transporte é necessária à realização de negócios. Por esta razão, é importante que o aumento da demanda por esta modalidade de transporte seja acompanhado de perto pela evolução da atividade regulatória, bem como pela implantação da infraestrutura necessária à prestação adequada do serviço.

Após esta análise, verificou-se que a alocação de slots ainda reflete o passado histórico do setor, baseado na atuação de poucos agentes. Conclui-se então que a regulação do setor deve evoluir no sentido de fomentar a concorrência e garantir incentivos a novos entrantes no mercado, o que somente trará benefícios aos passageiros e à economia. Para isso, é importante adaptar os mecanismos de acesso à escassa infraestrutura aeroportuária à nova realidade do setor, de modo a contribuir para a competitividade entre as companhias aéreas já consolidadas e os novos entrantes. 


\section{Referências}

Abreu, F. E. L. V. (2008) Análise sistêmica do setor aéreo brasileiro: propostas para o planejamento do setor. Dissertação (Mestrado em Transportes, Departamento de Engenharia Civil e Ambiental, Universidade de Brasília, Brasília.

Braga, L. G. T. B. (2009) O Papel da Agência Nacional de Aviação Civil - ANAC no Fomento da Competitividade entre as Empresas Aéreas de Transporte de Passageiros no Brasil: uma questão de sustentabilidade. Dissertação (Mestrado em Direito), Centro Universitário Curitiba, Curitiba.

Brasil. Conselho Administrativo de Defesa Econômica - CADE. Ato de Concentração n. 08012.009497/2010-84. Relator: Conselheiro Olavo Chinaglia. Brasília. J. em: 14/12/2011.

Fiuza, E. P. S. e Pioner, H.M. (2009) Estudo Econômico Sobre Regulação e Concorrência no Setor de Aeroportos. Rio de Janeiro: Agência Nacional de Aviação Civil - ANAC.

Franco, L. A.. A Regulação de Oferta no Mercado Brasileiro de Aviação Civil como Instrumento de Combate à Guerra de Preços: análise do mecanismo com base na teoria dos jogos. Revista do IBRAC, vol. 14, n. 02.

Ministério da Fazenda. Secretaria de Acompanhamento Econômico - SEAE. Parecer Analítico sobre Regras Regulatórias n. 003/COGTL/SEAE/MF, de 14 de junho de 2006.

Ministério da Fazenda. Secretaria de Acompanhamento Econômico - SEAE. Nota Técnica n. 29/2004/COGDC-DF/SEAE/MF. Ato de Concentração n. 08012.001291/2003-87.

Oliveira, A. V. M. (2009) Regulação da Oferta no Transporte Aéreo: do comportamento de operadoras em mercados liberalizados aos atritos que emergem da interface público-privado. In Schapiro, Mario Gomes (Coord.). Direito Econômico Regulatório. São Paulo: Saraiva.

Oliveira, A. V. M. (2007) Performance dos Regulados e Eficácia do Regulador: Uma Avaliação das Políticas Regulatórias do Transporte Aéreo e dos Desafios para o Futuro. In: Ronaldo Seroa da Motta; Lucia Helena Salgado e Silva. (Org.) Regulação e Concorrência no Brasil: Governança, Incentivos e Eficiência. Rio de Janeiro: Instituto de Pesquisa Econômica Aplicada, IPEA.

Reis, C. V. (2009) Regulação econômica dos serviços aéreos no Brasil: avaliação econômicofinanceira da empresa para a outorga dos serviços de transporte aéreo regular. Monografia (Especialização em Gestão da Aviação Civil) - Universidade de Brasília, Brasília. 